\title{
BMJ Global Health Systems thinking for health emergencies: use of process mapping during outbreak response
}

\author{
Kara N Durski D , , ${ }^{1,2}$ Dhamari Naidoo, ${ }^{1}$ Shalini Singaravelu, ${ }^{1}$ Anita A Shah, ${ }^{1}$ \\ Mamadou Harouna Djingarey, ${ }^{3}$ Pierre Formenty, ${ }^{1}$ Chikwe Ihekweazu, ${ }^{4}$ \\ James Banjura, ${ }^{5}$ Benoit Kebela, ${ }^{6}$ Adesola Yinka-Ogunleye, ${ }^{4}$ Ibrahima-Soce Fall, ${ }^{3}$ \\ Womi Eteng, ${ }^{4}$ Mohamed Vandi, ${ }^{5}$ Charles Keimbe, ${ }^{5}$ Anwar Abubakar, ${ }^{4}$ \\ Abulazeez Mohammed, ${ }^{7}$ Desmond E Williams, ${ }^{8}$ Margaret Lamunu, ${ }^{9}$ Sylvie Briand, \\ Jean Claude Changa Changa, ${ }^{10}$ Etienne Minkoulou, ${ }^{3}$ Dan Jernigan, ${ }^{8}$ \\ Demba Lubambo, ${ }^{3}$ Asheena Khalakdina, ${ }^{1}$ Ibrahim Mamadu, ${ }^{11}$ \\ Ambrose Talisuna (1) , ${ }^{3}$ Albert Mbule Kadiobo, ${ }^{12}$ Amara Jambai, ${ }^{5}$ Bruce Aylward, ${ }^{1}$ \\ Michael Osterholm²
}

To cite: Durski KN, Naidoo D, Singaravelu S, et al. Systems thinking for health emergencies: use of process mapping during outbreak response. BMJ Global Health 2020;5:e003901. doi:10.1136/ bmjgh-2020-003901

Handling editor Seye Abimbola

- Additional material is published online only. To view please visit the journal online (http://dx.doi.org/10.1136/ bmjgh-2020-003901).

Received 6 September 2020 Revised 11 September 2020 Accepted 13 September 2020

Check for updates

C) Author(s) (or their employer(s)) 2020. Re-use permitted under CC BY-NC. No commercial re-use. See rights and permissions. Published by BMJ.

For numbered affiliations see end of article.

Correspondence to

Kara N Durski; durskik@who.int

\section{ABSTRACT}

Process mapping is a systems thinking approach used to understand, analyse and optimise processes within complex systems. We aim to demonstrate how this methodology can be applied during disease outbreaks to strengthen response and health systems. Process mapping exercises were conducted during three unique emerging disease outbreak contexts with different: mode of transmission, size, and health system infrastructure. System functioning improved considerably in each country. In Sierra Leone, laboratory testing was accelerated from 6 days to within 24 hours. In the Democratic Republic of Congo, time to suspected case notification reduced from 7 to 3 days. In Nigeria, key data reached the national level in 48 hours instead of 5 days. Our research shows that despite the chaos and complexities associated with emerging pathogen outbreaks, the implementation of a process mapping exercise can address immediate response priorities while simultaneously strengthening components of a health system.

\section{INTRODUCTION}

Process mapping is a systems thinking approach used to understand, analyse, and optimise processes within complex systems. ${ }^{1}$ Process maps were first introduced in the early $1920 \mathrm{~s} ;{ }^{2}$ however, it was not until the 1980s that frameworks and methodologies which brought together various disciplines such as architecture, design and engineering were developed. This participatory methodology promotes collective thinking, facilitates communication among stakeholders and provides visualisation of challenges. ${ }^{3}$

To date, process mapping during outbreaks has not been documented, although it has

\section{Summary box}

There is little to no published research on process mapping being conducted during health emergencies to improve the current outbreak response.

- Our research shows that despite the chaos and complexities associated with emerging pathogen outbreaks, process mapping can address immediate response priorities while simultaneously strengthening components of a health system.

- This methodology could be applied to any country that has an outbreak, including COVID-19 cases.

- There is an acute need in the global health community to respond to disease outbreaks in a way that effectively uses limited resources.

- This is a user-friendly and low-cost methodology that can be implemented during any time point of an outbreak, including during preparedness and readiness activities.

- Future operational and implementation research focussed on using process mapping and other applied system methodologies during outbreaks should be conducted.

been applied in the health systems and healthcare field. It has been used to ensure optimisation of civil registration and vital statistics systems and in various healthcare quality improvement projects, from mapping the patient journey in a healthcare facility to redesigning procedures to increase efficiency in the USA and UK. ${ }^{14-6}$ It was used in South Africa to understand how the use of point of care tests for sexually transmitted infections, tuberculosis and HIV impacted care at large urban public healthcare clinics. ${ }^{7}$ Additionally, process mapping has been used to improve 
collaboration at the human-animal interface across a variety of sectors through the One Health Systems Mapping and Analysis Resource Toolkit (OH-SMART) ${ }^{8}$

Process mapping visually clarifies stakeholders' relationships and identifies bottlenecks, inefficiencies and design flaws that limit system performance. ${ }^{3}$ It can therefore be a useful tool for effective outbreak response when health systems become overloaded and basic health services cannot be maintained, allowing existing processes to be streamlined and strengthened instead of creating new ones. Mapping processes allows interactions, gaps and redundancies within the health system to be identified, captures complexities effectively and brings people together to share a common view of the system which are useful for developing solutions that can improve acute challenges as well as the long-term functionality of a health system. ${ }^{3}$ This methodology can support countries to leverage the incoming resources during response and recovery efforts, thus facilitating short-term and longterm health system strengthening. The flexibility of the methodology lends itself to being implemented in lowincome, middle-income and high-income countries alike and may be useful to address many of the operational complexities of the COVID-19 pandemic.

Process mapping exercises, which have proven to be an effective tool at optimising processes in other disciplines, can be a useful tool to assist with specific challenges during outbreak response. We aim to demonstrate how this methodology can be applied during any phase of a disease outbreak response so that processes can be streamlined to improve the current outbreak response as well as the long-term challenges in the information, clinical and laboratory systems.

\section{CONDUCTING PROCESS MAPPING EXERCISES}

Process mapping exercises were conducted during three unique disease outbreak contexts in Sierra Leone, the Democratic Republic of Congo (DRC) and Nigeria between 2014 and 2017. Each mapping exercise followed the same four-step methodology but had a unique focus based on the specificities of the disease outbreak, country context and health system. All addressed a challenge related to the health system either not functioning at an optimal level or being overwhelmed by the outbreak, or both. The process mapping methodology we used was adapted from the operations management discipline ${ }^{910}$ and Savigny $e$ t $a$ l's 'Applied Systems Thinking for Health Systems Research: a methodological handbook' ${ }^{3}$ to fit the context of a disease outbreak (figure 1). This adaptation was done to account for the limited time and resources available during an outbreak as they are dynamic and require quick interventions. One person with strong

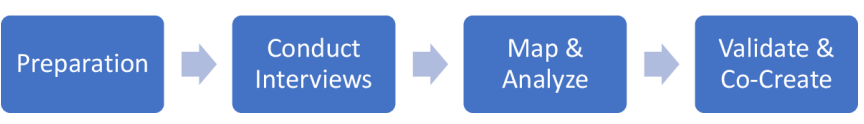

Figure 1 Mapping process. leadership, facilitation and coordination skills led the exercise and an additional one to two people (depending on the country and context) helped conduct the interviews.

\section{Preparation}

In step one, which took a few hours, big-picture operational challenges were identified with Senior Leadership and the Incident manager. Engagement and buy-in from senior leadership within the Ministry of Health $(\mathrm{MoH})$ or National Disease Control units is essential. Then the goals and objectives for each process mapping exercise were defined according to challenges of each outbreak. Indicators were identified to measure the effectiveness of the process re-design. The indicators collected varied according to the process being mapped and the operational context in which the outbreak was occurring. Organisations, partners and stakeholders who were impacted by or involved with the process were also identified.

\section{Conduct interviews}

Next, individual interviews lasting up to 1 hour were conducted with all persons identified during step 1 . Stakeholders were encouraged to provide honest and constructive opinions during the discussions. Interviews focussed on obtaining specific knowledge regarding the step-by-step process related to the main operational challenge being mapped including obtaining an understanding of their specific responsibilities and roles, the roles and responsibilities of their colleagues, challenges that they encounter within the health system, barriers that prevent the health system from operating at an optimal level, barriers that prevent the current response from operating at an optimum level, specific pain points (ie, challenges) in the current process, and general systematic challenges that impact the process. If stakeholders not initially identified during step 1 were mentioned as instrumental to the process, they were also contacted and interviewed.

\section{Map and analyse}

Next, each step in the process, as documented during the interviews, was drawn out and visually mapped with pen and paper. Prior to the group re-design session, this was put into an electronic format to improve legibility for all stakeholders.

\section{Validate and co-create}

A group re-design session was then held with all stakeholders to validate the process map and to ensure there were no missing pain points or challenges in the process. Solutions were ideated and then prioritised according to the costs and length of time to implement them, availability and willingness of persons and organisations to implement and monitor changes, and perceived benefit to the response and health system. This phase served to bring all parties to a common understanding of the challenges and to co-create solutions which would improve 
the response and contribute to the strengthening of the health system. Implementation of changes began immediately after the re-design session and were measured approximately 7 to 10 days later. Implementation was performed by partners and stakeholders involved in the process mapping exercise according to their mandate and/or interest in the solution. The authors did not fully implement the re-design in any of the case studies as this required human and financial resources; therefore, the indicators described are baseline and post-mapping exercise, pre-full implementation.

\section{CASE STUDY 1: EBOLA IN SIERRA LEONE}

Ebola virus causes a severe disease with average case fatality rate of $50 \% .{ }^{11}$ It is a zoonosis which spreads in rare events from animals to humans and then is sustained in the human population through human-to-human transmission. ${ }^{11}$ An Ebola virus disease (EVD) outbreak was reported for the first time in Sierra Leone's history in June 2014. This context rendered a complex response which was further compounded by a weak health system, limited surveillance and laboratory capacity, few hospitals and clinics with appropriate isolation facilities, an urban setting with overcrowding and poor sanitation, and general population distrust of the government. ${ }^{12} 13$ The first Ebola case was reported in early June in Kailahun District, over 250 miles from Freetown, the capital of Sierra Leone. ${ }^{14}$ This resulted in the largest known Ebola outbreak to date with over 14124 cases and 3956 deaths in Sierra Leone alone. ${ }^{15}$

The process mapping exercise was conducted in Freetown, Sierra Leone, in December 2014 to address the challenges associated with an urban outbreak. The process mapping exercise was conducted over the course of 3 days, 6 months after the first cases had been identified in Freetown. The outbreak ended on 17 March 2016. ${ }^{15}$ At this time, Western Area, the province in which Freetown is located, had $40 \%$ of the confirmed EVD cases in the country, with approximately 26 confirmed cases and 82 new suspected cases each day. ${ }^{16}$ There were five laboratories and 13 Ebola treatment units (ETUs) and holding centres (HCs) providing services for Western Area at this time. Due to capacities in Western Area being overloaded, patients and/or samples were transferred to other districts accordingly.

The objective of the process mapping exercise was to understand why there were delays in obtaining patient results. These delays were impacting the entire response: patient treatment, case investigation and contact tracing teams, quarantine units, families and overall outbreak coordination. The exercise was conducted with $\mathrm{MoH}$ officials with support from the WHO and Centers for Disease Control and Prevention (figure 2). Interviews were conducted with over 30 persons, including incident manager, epidemiologists, clinicians, nurses, logisticians, community engagement experts, and laboratory specialists.
A list of pain points were identified, revealing several main themes: (1) delayed results-this impacted triaging patients in HCs which affected patient safety and early treatment, propagated nosocomial transmission and kept EVD patients in the ETUs longer than necessary after recovery, resulting in valuable bed space being occupied unnecessarily; (2) lack of information systems-there was no process for data (patient result, epidemiological and operational) to be consolidated and managed; (3) inefficient communication-there was no process in place to ensure results were given to the correct person/team at the correct time for correct action and insufficient communication between teams; and (4) lack of human resources and capacity - there were not enough trained staff to carry out necessary functions. Once the pain points were identified and mapped, all pillars within the incident management structure convened and systemwide solutions were ideated, developed and implemented (online supplemental chart 1).

Prior to conducting the process mapping exercise, it took on average 6 days for laboratory results to reach the intended audience. After partial implementation of changes, it took an average of 24 hours. The impact of the exercise was far-reaching with an improved turnaround time and turnover of patients in the ETUs and HCs. Better communication between all pillars within the Incident Management System (IMS) resulted in the improvement of critical services such as quarantined homes receiving food faster and better communication with families so they knew where their loved ones were. This improved overall engagement with the response and helped reduce distrust of the response. Additionally, the $\mathrm{MoH}$ was able to report on the number of confirmed cases with greater accuracy and timeliness to the public, partners and donors. Furthermore, operational analyses could be performed to drive operational planning, including identification of hotspots and implementation of targeted risk communications.

\section{CASE STUDY 2: YELLOW FEVER IN THE DEMOCRATIC REPUBLIC OF CONGO}

A large multicountry yellow fever (YF) outbreak began in Angola in late December 2015 and soon spread to neighbouring DRC in March 2016. ${ }^{17} \mathrm{YF}$ is an acute viral haemorrhagic disease transmitted by mosquitoes. DRC has a weak health system, with an estimated $70 \%$ of the population having little or no access to healthcare. ${ }^{18} \mathrm{It}$ is a large, populated country with 81 million residing in 26 provinces that span 2.3 million sq km. ${ }^{19}$ From 22 March 2016 through 20 July 2016, 1,907 suspected cases, 68 confirmed cases and 95 deaths were reported in DRC alone. ${ }^{17}$ The last confirmed non-sylvatic case had symptom onset on 12 July $2016 .^{20}$ Although cases of YF are regularly reported in DRC, ${ }^{21} \mathrm{YF}$ outbreaks in high density areas are unusual, therefore the cases of $\mathrm{YF}$ in an urban setting necessitated a different response strategy to that of a rural outbreak. 


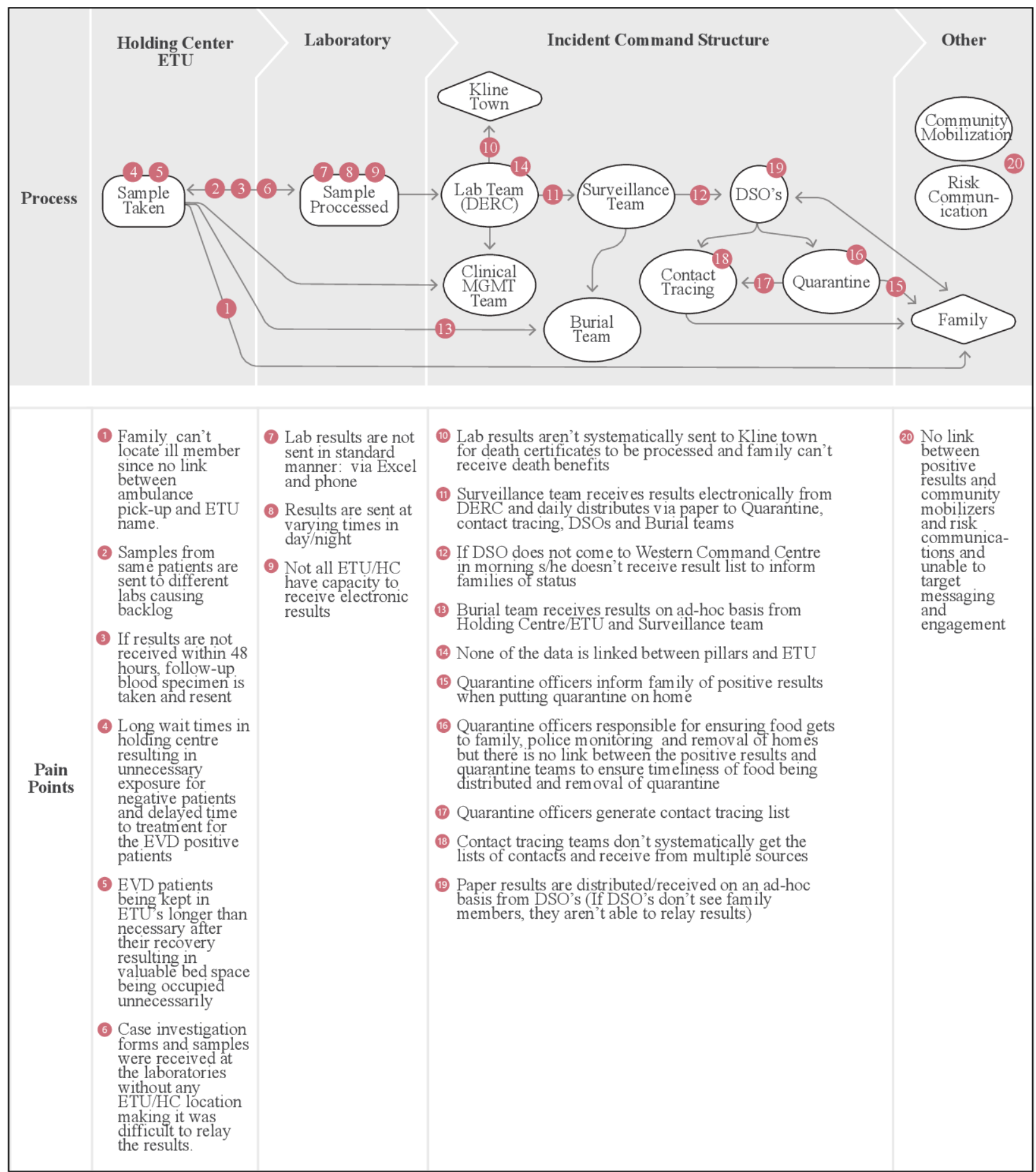

Figure 2 Process mapping exercise: Ebola in Sierra Leone. DERC, District emergency response center; DSO, district surveillance officer; ETU, Ebola treatment units; EVD, Ebola virus disease; $\mathrm{HC}$, holding centres, Mgmt, management.

A process mapping exercise was conducted in Kinshasa, DRC, to address the challenges related to the flow of information from the community to the national $\mathrm{MoH}$ level (figure 3). The exercise ran over the course of 1 week in late June/early July 2016, 4 months after the first case was confirmed. At the time of the process mapping exercise, there was a backlog of data across several districts in DRC and little confidence surrounding the numbers of suspected and confirmed cases. Delays in testing and limited epidemiological data posed challenges as it was difficult to assess whether the current response strategy was adequate. Thus, the national Incident Management System was unable to understand the full extent of the outbreak and unable to make key decisions regarding important response factors such as where health staff should be located, planning and implementation of the vaccination campaign, and surveillance and laboratory activities. The process mapping exercise was conducted with $\mathrm{MoH}$ officials with support from the WHO and Institut National de Recherche Biomédical. Interviews 


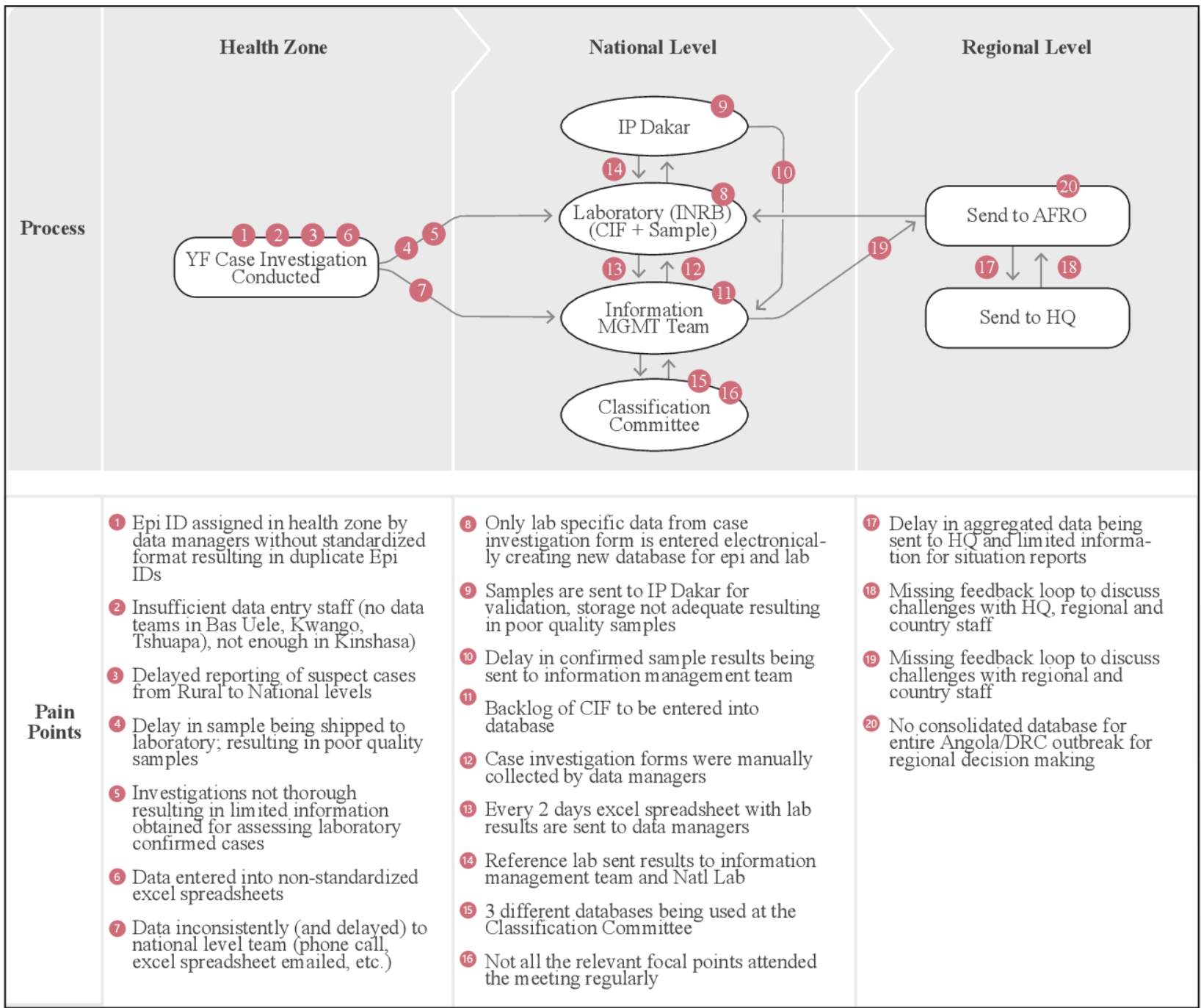

Figure 3 Process mapping exercise: yellow fever im the Democratic Republic of Congo. AFRO, Africa regional office, CIF, case investigation form; DRC,Democratic Republic of Congo; HQ, headquarters; INRB, Institut National de Recherche Biomédical; IP, Institute Pasteur; MGMT, management; YF, yellow fever.

were conducted with over 20 incident managers, epidemiologists, data managers, data scientists, and laboratory specialists.

A few key themes in the pain points were identified: (1) lack of standardised processes and procedures-case investigation and laboratory forms were often missing, inaccurate or incomplete further affecting data accuracy; (2) lack of information sharing-there was insufficient collaboration and data sharing between key members working on the outbreak; (3) lack of human resourcesthere was insufficient staffing to manage the movement of samples and data and no designated data entry person, resulting in delays in updating and cleaning the data; and (4) suboptimal information systems-comparisons between the national level surveillance database and national level laboratory database revealed a discrepancy of more than 280 patient records and a backlog of over 90 paper case investigation forms (CIFs) that were yet to be entered into the database. The data was not archived regularly and was stored on an individual staff member's computer. Other peripheral challenges mentioned included the sample storage and shipment and there was a lack of standardised YF case definitions, making it difficult to classify suspected, probable and confirmed cases. Following the identification of the pain points, a variety of solutions were proposed, with the implementation focussed on the development of processes and procedures, and associated data management solutions (online supplemental chart 1).

Prior to conducting the process mapping exercise, it took, on average, 7 days to be notified of a suspected case of YF. After partial implementation, this was reduced to an average of 3 days. The recommended actions improved the daily flow of data allowing the national IMS structure to obtain a clear picture of the epidemiological situation which is required for decision making. It also catalysed a review of the placement of the mobile laboratories, the mapping of cases to understand movement of the outbreak and the use of modelling to better plan the distribution of the YF vaccination to the areas that 
needed it the most. Furthermore, the review and adaptation of the YF case definition, followed by the training of health workers, significantly improved case detection and reporting.

\section{CASE STUDY 3: MONKEYPOX IN NIGERIA}

In September 2017, Nigeria experienced its first monkeypox outbreak since $1978 .{ }^{22}{ }^{23}$ Prior to this outbreak, monkeypox was not a priority disease in Nigeria, with little or no awareness of the disease among health workers and no surveillance system in place. Monkeypox is a rare viral zoonotic disease with the average case fatality rate of up to $11 \% .{ }^{24}$ At the time of the outbreak, there was no approved treatment or vaccine available, although prior smallpox vaccination was found to be highly effective at preventing the infection. The disease is spread primarily through an animal reservoir, although human-to-human transmission has been documented. ${ }^{25}$ Nigeria is a large, densely populated country with a de-centralised health system, giving each state significant autonomy in managing public health activities. ${ }^{26}$ Additionally, over half of the population lives below the poverty line on less than 1 dollar a day, with only $43 \%$ of the population having access to healthcare. ${ }^{27}$ This poses serious challenges in coordinating a multistate outbreak. The outbreak resulted in sporadic cases over the course of the next year with a total of 122 confirmed or probable cases being identified and seven deaths as of 15 September $2018 .^{28}$

The mapping exercise was conducted over the course of 1 day in Abuja, the capital of Nigeria, 2 days after the monkeypox outbreak was confirmed. The objective of this exercise was to understand the total number of suspected and confirmed cases, their geographical location and the associated operational challenges to assess the extent of the outbreak and to inform resource allocation efforts. At the time of the mapping, cases were confirmed in one state with suspected cases in six other states, resulting in a potential wide geographic spread. ${ }^{26}$ The mapping exercise was conducted in parallel to the national IMS structure being established, technical guidance documents and standard operating procedures (SOPs) being written and laboratory capacity being established. ${ }^{23}$ The process mapping exercise was conducted with Nigeria's Centres for Disease Control (NCDC) with support from the WHO. Interviews were conducted with over 15 incident managers, medical officers, epidemiologists, data managers and laboratory specialists (figure 4).

The primary pain points themes that emerged included: (1) information management system challenges-incomplete information from CIFs resulted in limited understanding of the total number and location of suspected cases; (2) data collection challenges-incomplete investigations and collection of samples by surveillance officers which limited IMS' understanding of the situation in each of the states; and (3) communication of information. Other peripheral challenges were mentioned, such as insufficient number of isolation areas in the hospitals, sample storage issues-some samples were not properly stored impeding the laboratories analysis, limited personal protective equipment for clinicians, and lack of staff to conduct investigations and contact tracing. After the pain points were discussed and agreed upon, a list of solutions was ideated and implemented. These solutions focussed on improving the level of engagement between the national level and states, training staff, establishing guidance and SOPs for the IMS and surveillance teams, and detailing responsibilities and timelines for all personnel working on the outbreak (online supplemental chart 1).

Prior to conducting the process mapping exercise, it took an average of 5 days to receive the CIF and case pictures at the NCDC national level. After the implementation of changes, it took an average of 48 hours. Furthermore, there was only a 24-hour delay in consolidating the data, resulting in timely reporting of the suspected and confirmed cases to the incident manager. These changes enabled the IMS to make faster decisions regarding the allocation of resources to the affected states and allowed for timely reporting of case counts which could be shared with the public. Additionally, timely information supported the development of associated risk communication, faster contact tracing to limit the spread of disease and more effective deployment of personal protective equipment to affected districts.

\section{LESSONS LEARNT}

Our findings demonstrate the importance of using process mapping during disease outbreaks as a tool to aid in the response while strengthening components of an already existing health system. This may be a particularly useful methodology to deploy during the current COVID-19 pandemic when there are many operational challenges and complexities. This is a methodology that epidemiologists, logisticians, community engagement experts, clinicians, infection prevention and control experts, laboratory specialists and incident managers could familiarise themselves with as they are often the first individuals to work within the response system.

Process mapping should be considered at any phase of outbreak response to assess system-wide challenges and provide on-going monitoring of system improvements. They may also be done during International Health Regulations preparedness and readiness efforts and during post-event after-actions reviews. All three outbreaks occurred in sub-Saharan Africa which may limit generalisability of results; however, process mapping exercises have been done across numerous industries and settings around the world ${ }^{15-9} 2930$ and we therefore believe this methodology could be applied to outbreaks in all geographic settings and in low-income, middle-income and high-income countries alike. The authors encourage others to implement process mapping exercises during outbreak response to strengthen the generalisability and 


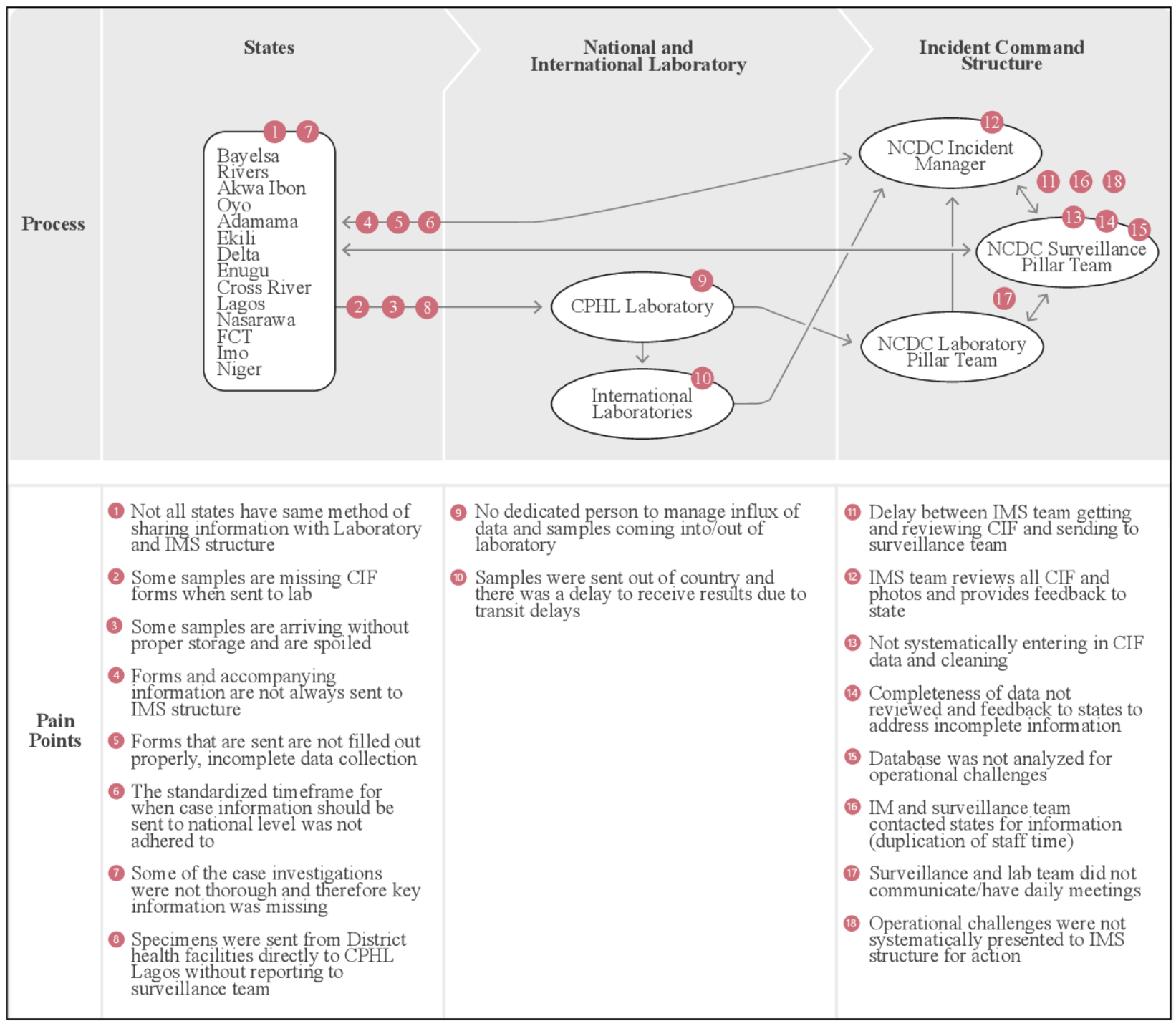

Figure 4 Process mapping exercise:monkeypox in Nigeria. CIF, case investigation forms; CPHL, Central public health laboratories; NCDC, Nigeria Centers for Disease Control.

evidence base for this methodology. Furthermore, the length of time from the start of outbreak to the initiation of the mapping exercise varied and therefore the authors believe it is a useful methodology that can be deployed at any time point during an any outbreak to assist in solving complex operational challenges. Additional research should be performed to evaluate how the timing of the process mapping exercise impacts the processes; however, from our experience, the earlier the process mapping is conducted, the less challenging the re-design is, as there are fewer complexities and interactions that need to be addressed. This exercise was done to strengthen the flow of information and data associated with surveillance, clinical and laboratory systems. The authors recommend using process mapping in other contexts within an outbreak to improve generalisability to other areas of a health system.

The primary challenges in implementing this methodology during an outbreak included: (1) obtaining time from stakeholders to conduct the interviews and re-design session; (2) allocating human and financial resources to re-design the processes; and (3) changing priorities and epidemiological situation. Based on these challenges, we found an added level of situational awareness, openness and flexibility is required by the persons conducting the exercise as well as those involved in the re-design as time is limited and the situation is evolving rapidly. Ensuring buy-in from leadership, and strong stakeholder and partner engagement from the beginning was crucial as it allowed for human and financial resource support during the implementation of solutions. This also promoted accountability of stakeholders and partners during the implementation of the solutions. Keeping the interview time to under 1 hour per person reduced pressures associated with timing. During the re-design process, we also highlighted the importance of a growth mindset which allowed for innovative approaches to be discussed and implemented. Designating one person to monitor 
the process through the outbreak and beyond will also support the sustainability of the re-designed process.

\section{CONCLUSION}

The three outbreaks described had unique challenges and varying levels of complexity, including the size (number and geographic dispersion), duration (the length of the outbreak prior to the mapping exercise being conducted) and the existence of functioning systems. They also had many similarities. All outbreaks had challenges associated with the flow of data and information systems which impacted operational and strategic decision-making required to rapidly guide the responses. A common challenge across all scenarios was ensuring sufficient and trained staff had clear responsibilities, timelines and built-in accountability mechanisms. Each scenario also necessitated improving the working relationship and strengthening communication and coordination between the laboratory, clinical and surveillance teams. All three countries had already existing systems that managed data and flow of information prior to the outbreak. However, all the systems were overwhelmed once the number of suspected cases increased. The impact on the process mapping exercise in all three countries was witnessed within days: communication between stakeholders was enhanced, strategic decisions were made possible with good data, and ancillary and supportive health system services improved. We aimed to re-design resilient processes that evolve as the situation allows, and therefore, the process mapping exercise should be reassessed and repeated as necessary to allow for further system refinement. A challenge associated with this is ensuring sufficient resources to monitor, re-evaluate and re-adjust the processes over time, and the authors suggest that this be built into the mapping exercise during the planning stage. This re-evaluation and re-adjustment concept are a key activity required for long-term health system strengthening and the authors believe long-term positive change will be noticed as has been demonstrated through process mapping exercises in other disciplines. ${ }^{15-10} 29-31$

The solutions created were often simple yet had tremendous impact. Moreover, financial requirements were minimal and consisted of only staff time. The full implementation of the re-design can have financial costs; however, as demonstrated, there are innovative ways to address process-related issues that are no-to-low cost such as improving communication between teams, establishing clear roles, using organisational tools such as stamp pads, responsibilities and timelines, ensuring all persons and teams understand their own purpose and roles along with those whom they should be working closely with, and writing SOPs and ensuring everyone is adequately trained on them.

\footnotetext{
Author affiliations

${ }^{1}$ World Health Organization, Geneve, Switzerland

${ }^{2}$ University of Minnesota School of Public Health, Minneapolis, Minnesota, USA
}

${ }^{3}$ World Health Organization, Brazzaville, Republic of Congo

${ }^{4}$ Nigeria Centre for Disease Control, Abuja, Nigeria

${ }^{5}$ Sierra Leone Ministry of Health and Sanitation, Freetown, Sierra Leone

${ }^{6}$ Ministry of Health Democratic Republic of Congo, Kinshasa, Democratic Republic of Congo

${ }^{7}$ Africa Centres for Disease Control and Prevention, Addis Ababa, Ethiopia

${ }^{8}$ Centers for Disease Control and Prevention, Atlanta, Georgia, USA

${ }^{9}$ World Health Organization, Freetown, Sierra Leone

${ }^{10}$ Institut National de Recherche Biomédicale, Kinshasa, Democratic Republic of

Congo

${ }^{11}$ World Health Organization, Abuja, Nigeria

${ }^{12}$ World Health Organization, Kinshasa, Democratic Republic of Congo

\section{Twitter Kara N Durski @KaraDurski}

Acknowledgements We thank Michael de St. Aubin for his support in designing the graphics and Yolana Pollak for her support in editing the manuscript.

Contributors KND, MHD, Cl, BK, ISF, MAV, DEW, SB, DJ, AK, AJ, BW and MO ideated the project. KND, DN, SS, AS, MHD, PF, Cl, JB, BK, AYO, ISF, WE, MAV, CK, AA, AM, DEW, ML, SB, JCCC, EM, DN, DL, AK, IB, AT, AMK, AJ, BA and MO contributed to writing the initial draft of the manuscript. KD, DN, SS, AS, MHD, JB, AUO, WE, CK, AA, AM, DEW, ML, JCCC, EM, DJ, DL, IM, AL and AMK worked on the methodology and mapping. All authors reviewed and contributed to the final manuscript.

Funding The authors have not declared a specific grant for this research from any funding agency in the public, commercial or not-for-profit sectors.

Competing interests None declared.

Patient and public involvement Patients and/or the public were not involved in the design, or conduct, or reporting, or dissemination plans of this research.

Patient consent for publication Not required.

Provenance and peer review Not commissioned; internally peer-reviewed.

Data availability statement There are no data in this work.

Open access This is an open access article distributed in accordance with the Creative Commons Attribution Non Commercial (CC BY-NC 4.0) license, which permits others to distribute, remix, adapt, build upon this work non-commercially, and license their derivative works on different terms, provided the original work is properly cited, appropriate credit is given, any changes made indicated, and the use is non-commercial. See: http://creativecommons.org/licenses/by-nc/4.0/.

\section{ORCID iDs}

Kara N Durski http://orcid.org/0000-0003-1456-626X

Ambrose Talisuna http://orcid.org/0000-0001-6436-3415

\section{REFERENCES}

1 Antonacci G, Reed JE, Lennox L, et al. The use of process mapping in healthcare quality improvement projects. Health Serv Manage Res 2018;31:74-84.

2 Graham BB. Detail process charting: speaking the language of process. Hoboken, N.J: Wiley, 2004.

3 de Savigny D, Blanchet K, Adam T. Applied systems thinking for health systems research. London: Open University Press, 2017.

4 AbouZahr C, de Savigny D, Mikkelsen L, et al. Towards universal civil registration and vital statistics systems: the time is now. Lancet 2015;386:1407-18.

5 Trebble TM, Hansi N, Hydes T, et al. Process mapping the patient journey: an introduction. BMJ 2010;341:c4078.

6 Damato AL, Lee LJ, Bhagwat MS, et al. Redesign of process map to increase efficiency: reducing procedure time in cervical cancer brachytherapy. Brachytherapy 2015;14:471-80.

7 Stime KJ, Garrett N, Sookrajh Y, et al. Clinic flow for STI, HIV, and TB patients in an urban infectious disease clinic offering point-ofcare testing services in Durban, South Africa. BMC Health Serv Res 2018;18:363.

8 Errecaborde KM, Pelican KM, Kassenborg H, et al. Piloting the one health systems mapping and analysis resource toolkit in Indonesia. Ecohealth 2017;14:178-81.

9 Madison D, mapping P. process improvement and process management: a practical guide to enhancing work flow and information flow. Chico, CA: Paton Professional, 2005. 
10 Landel R, Snyder A. Business process mapping. Charlottesville, VA: Darden School of Business, 2010.

11 World Health Organization (WHO). Ebola virus disease fact sheet Available: https://www.who.int/news-room/fact-sheets/detail/ebolavirus-disease [Accessed 16 Dec 2019].

12 Cancedda C, Davis SM, Dierberg KL, et al. Strengthening health systems while responding to a health crisis: lessons learned by a nongovernmental organization during the Ebola virus disease epidemic in Sierra Leone. J Infect Dis 2016;214:S153-63.

13 Marston BJ, Dokubo EK, van Steelandt A, et al. Ebola response impact on public health programs, West Africa, 2014-2017. Emerg Infect Dis 2017;23.

14 World Health Organization (WHO). Ebola in Sierra Leone: a slow start to an outbreak that eventually outpaced all others, 2015. Available: http://www.who.int/csr/disease/ebola/one-year-report/sierra-leone/ en/ [Accessed 16th Dec 2019].

15 Centers for Disease Control and Prevention (CDC). 2014-2016 Ebola outbreak in West Africa. Available: https://www.cdc.gov/vhf/ebola/ history/2014-2016-outbreak/index.html [Accessed 16th December 2019].

$16 \mathrm{WHO} / \mathrm{MoH}$ EDPLN Ebola Laboratory Database. Average of confirmed and suspected cases during the month of December 2014.

17 World Health Organization (WHO). Yellow fever situation report, 2016. Available: http://www.who.int/emergencies/yellow-fever/ situation-reports/29-july-2016/en/ [Accessed 16th Dec 2019].

18 Ilunga-llunga $F$, Levêque A, Laokri S, et al. Incidence of catastrophic health expenditures for households: an example of medical attention for the treatment of severe childhood malaria in Kinshasa reference hospitals, Democratic Republic of Congo. J Infect Public Health 2015;8:136-44.

19 Central Intelligence Agency (CIA). The world Factbook: Democratic Republic of the Congo. Available: https://www.cia.gov/library/ publications/the-world-factbook/geos/cg.html [Accessed 16th Dec 2019].

20 World Health Organization (WHO). Yellow fever situation report, 2016. Available: https://www.who.int/emergencies/yellow-fever/ situation-reports/28-october-2016/en/ [Accessed 16 Dec 2019].
21 Ingelbeen B, Weregemere NA, Noel H, et al. Urban yellow fever outbreak-Democratic Republic of the Congo, 2016: towards more rapid case detection. PLoS Negl Trop Dis 2018;12:e0007029.

22 Durski KN, McCollum AM, Nakazawa Y, et al. Emergence of Monkeypox - West and Central Africa, 1970-2017. MMWR Morb Mortal Wkly Rep 2018;67:306-10.

23 Yinka-Ogunleye A, Aruna O, Ogoina D, et al. Reemergence of human monkeypox in Nigeria, 2017. Emerg Infect Dis 2018;24:1149-51.

24 World Health Organization (WHO). Monkeypox fact sheet. Available: https://www.who.int/news-room/fact-sheets/detail/monkeypox [Accessed 16th December 2019].

25 Central Intelligence Agency (CIA). The world Factbook: Nigeria. Available: https://www.cia.gov/library/publications/the-worldfactbook/geos/ni.html [Accessed 16 Dec 2019].

26 Nigeria Centre for Disease Control (NCDC). Nigeria monkeypox monthly situation report, 2017. Available: https://ncdc.gov.ng/ themes/common/files/sitreps/75945df434ec5604d2f9ffd2201a8beb. pdf [Accessed 16 Dec 2019].

27 Welcome MO. The Nigerian health care system: need for integrating adequate medical intelligence and surveillance systems. J Pharm Bioallied Sci 2011;3:470-8.

28 Yinka-Ogunleye A, Aruna O, Dalhat M, et al. Outbreak of human monkeypox in Nigeria in 2017-18: a clinical and epidemiological report. Lancet Infect Dis 2019;19:872-9.

29 Fattah Z, Kondratenko A, Lovat F. The British airways service delivery process, 2008. Available: https://www.slideshare.net/ mrlovat/the-british-airways-service-delivery-process [Accessed 16 Dec 2019].

30 Mind Tools. Improving business processes: streamlining tasks to improve efficiency, 2016. Available: http://www.mindtools.com/ pages/article/improving-business-processes.htm [Accessed $16 \mathrm{Dec}$ 2019].

31 NHS Institute for Innovation and Improvement. Improvement leaders guide: NHS process mapping, analysis and redesign, 2005. www. institute.nhs.uk/improvementguides 